\title{
Enamel Microabrasion Combined with in-Office Bleaching in Treating with Moderate to Severe Dental Fluorosis: A Randomized Clinical Trial
}

\author{
Yingjuan Lu", Jieqi Wang"\#, Rui Gao ${ }^{2 \#, ~ Y a n c a n ~ L i a n g ~}{ }^{1}$ and Shaohai Chang*1 \\ ${ }^{1}$ Department of Stomatology, Sun Yat-Sen Memorial Hospital, Sun Yat-Sen University, China \\ ${ }^{2}$ Shenzhen Birth Cohort Study Centre, Nanshan Maternity \& Child Healthcare Hospital, China \\ \#These authors contributed equally to this work
}

*Corresponding author: Shaohai Chang, Department of Stomatology, Sun Yat-Sen Memorial Hospital, Sun Yat-Sen

University, China

ARTICLE INFO

Received: February 18, 2021

Published: 慧 February 23, 2021

Citation: Yingjuan Lu, Jieqi Wang, Rui Gao, Yancan Liang, Shaohai Chang. Enamel Microabrasion Combined with in-Office Bleaching in Treating with Moderate to Severe Dental Fluorosis: A Randomized Clinical Trial. Biomed J Sci \& Tech Res 34(2)-2021. BJSTR. MS.ID.005510.

\begin{abstract}
Statement of Problem: The stained dental fluorosis affects the beauty and selfconfidence of the patients. How to treat these patients safely and effectively is being explored by the clinicians. Enamel microabrasion has been widely used in treating dental fluorosis, and this method can be combined with at-home bleaching to improve the efficacy. However, this combined treatment was generally applied to patients with mild-to-moderate dental fluorosis. Whether this treatment can be used in severe dental fluorosis is unknown. Additionally, at-home bleaching is patient-applied and timeconsuming. Therefore, microabrasion combined with professional in-office bleaching may be a better choice. However, whether the enamel microabrasion enhances the risk of dental sensitivity of in-office bleaching remain unclear.
\end{abstract}

Purpose: This parallel, clinical, randomized controlled trial (RCT) aimed to evaluate the efficacy and sensitivity of enamel microabrasion combined with in-office bleaching in treating stained dental fluorosis.

Material and Methods: A total of 60 adult patients with dental fluorosis treated at our Hospital were randomly divided into two groups ( $\mathrm{n}=30$ in each group). The patients in group 1 received enamel microabrasion combined with 35\% hydrogen peroxide for in-office bleaching. The patients in group 2 only received $35 \%$ hydrogen peroxide for bleaching. The area ratio (a) of fluoride staining of six maxillary anterior teeth of the two groups before and after the treatment was compared. The differences in fluorosis area ratio of maxillary anterior teeth $(\Delta \mathrm{a})$ and visual analog scale (VAS)1 before and after the treatment were further compared. The tooth sensitivity ratio $(S)$ of the patients and VAS2 were also compared. The rank-sum test was used to analyze a, $\triangle \mathrm{a}$, VAS1 and VAS2. The Fisher exact probability method was used to analyze the sensitivity rate.

Results: Both treatments reduced the area ratio of fluoride staining. The decrease in $\Delta$ a was more in group 1 than in group 2 and the patients were more satisfied with the treatment. However, the patients were more sensitive (VAS2) in group 1.

Conclusions: In-office bleaching can improve moderate and severe dental fluorosis. The effect of the combination of enamel microabrasion and bleaching is better. The choice of treatment should take into account the patient's esthetic requirements and the individual differences in the degree of acceptance.

Clinical Implications: This study compared the efficacy and tooth sensitivity of enamel microabrasion combined with in-office bleaching and in-office bleaching only in treating stained dental fluorosis.. Our founding may provide a novel choice for treating moderate and severe dental fluorosis 


\section{Introduction}

Dental fluorosis is a special enamel dysplasia caused by excessive intake of fluoride during tooth development and mineralization. It is the most common and prominent symptom in the early stage of chronic fluorosis. The clinical manifestations of dental fluorosis are symmetrical white stripes or patches on the tooth surface [1]. Some serious cases, such as Dean's grading 3 and 4 dental fluorosis, have yellow-brown patches on the tooth surface [2]. The stained dental fluorosis affects the beauty and self-confidence of the patients [3]. Therefore, how to treat these patients safely and effectively is being explored by the clinicians. The clinical treatment methods of dental fluorosis are generally divided into invasive and noninvasive methods. The invasive method is to solve the aesthetic problem of tooth thoroughly by repairing the porcelain veneer. The noninvasive bleaching of teeth is done using peroxide. Because peroxide just can remove the superficial layer of staining, bleaching has not been advocated as a sole treatment of moderate or severe dental fluorosis [4]. But there are some patients who do not require a complete change of stained tooth surface because they cannot pay so much money for the porcelain veneer or they don't want to remove too much enamel. They may prefer to accept bleaching as their treatment method. However, whether bleaching can improve the stained dental fluorosis is unclear.

Bleaching can combine with other treatment to improve the efficacy [5,6]. In recent years, a novel treatment called enamel microabrasion has been used in treating dental fluorosis [7]. Enamel microabrasion technique is to remove/reduce the staining area on the enamel surface using $37 \%$ phosphoric acid and pumice [5]. However, no definite conclusion exists regarding whether bleaching combined with enamel microabrasion is effective against moderate or severe dental fluorosis. In addition, bleaching is of two types: at-home tooth bleaching and in-office tooth bleaching. Because the effect of at-home bleaching is patient-applied and timeconsuming, also, due to improper manipulation of the patient, the bleaching agent sometimes overflows from the tray, damaging the gingival tissue $[8,9]$. Therefore, in-office bleaching by professional clinicians may be the first choice for patients. But compared to at-home bleaching, in-office bleaching may cause more tooth sensitivity [4]. Whether combined with the enamel microabrasion enhances the risk of dental sensitivity of in-office bleaching remains unknown. Thus, the aim of this trial was to observe the efficacy and tooth sensitivity of enamel microabrasion combined with in-office bleaching and in-office bleaching only in treating moderate and severe dental fluorosis

\section{Material and Methods}

This study was approved by the local ethics and research committee (SYSEC-KY-KS-2018-030) and is registered in China Clinical Trials Registry (ChiCTR1800016630). The design of this RCT followed the guidelines published by the Consolidated Standards of Reporting Trials $[9,10]$. From January 2018 to August
2018, 72 patients with dental fluorosis at our Hospital were enrolled for the study. All patients signed informed consents. The inclusion criteria were as follows: age 18-50 years; diagnosis of fluorosis using the modified Dean's index criteria with a range of 0 (normal), 0.5 (questionable), 1 (very mild), 2 (mild), 3 (moderate), and 4 (severe) [11]; fluorosis Dean's grading 3 and 4; no dental caries and periodontitis; good oral and general health; no mental disorder; no large area filling and crown restorations; and patients' informed consent for treatment. The exclusion criteria were as follows: pregnant and lactating women; allergy to test products; and structural cracks on the enamel surface. A total of 60 patients were enrolled according to the screening criteria. A blinded evaluator recorded the patient's tooth staining using a digital camera (Canon EOS 600D, Tokyo, Japan) with a lens (Canon EF, 100mm) of the same shutter speed $(1 / 200)$ and the aperture $(F / 11)$ in the indoor natural light. The camera was placed directly in front of the patient, and the lens was perpendicular to the maxillary incisor lip surface. The area of tooth staining and the total area of six maxillary anterior teeth were measured using image software (Figure 1).

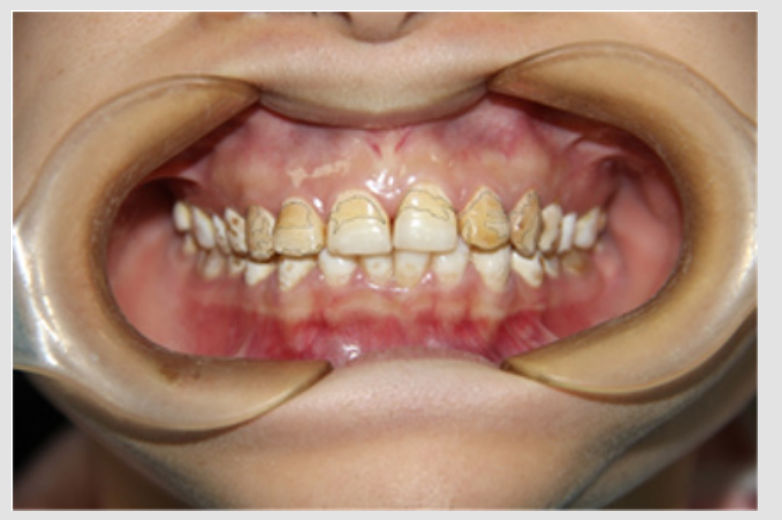

Figure 1: Calculation of the discolored area using the software (PhotoShop; discolored area 40.04\%).

\section{Sample Size Calculation}

The sample size was calculated based on a pilot study. A twosided test with alpha of $5 \%$ and $80 \%$ power was used to detect a difference of $20 \%$ between the groups for removing fluorosis stains with Dean's grading 3 and 4 . The sample size of each group needed to be at least 25 . The sample size calculation formula was as follows [12]:

$$
\begin{gathered}
n=2\left(\sigma \frac{z_{1}-\alpha /(2 \tau)+z_{1}-\beta}{\mu_{A}-\mu_{B}}\right)^{2} \\
1-\beta=\phi\left(Z-Z_{1-\alpha /(2 \tau)}\right)+\phi\left(-Z-Z_{1-\alpha /(2 \tau)}\right), Z=\frac{\mu_{A}-\mu_{B}}{\sigma \sqrt{\frac{2}{n}}}
\end{gathered}
$$

In this formula, $\mathrm{n}$ is the sample size; the standard normal distribution function $\Phi$ is 10 ; type I error $\alpha$ is $5 \%$; $\tau$ is the number of comparisons to be made; and $\beta$ is type II error; the power of $1-\beta$ is 0.80 . 


\section{Randomization}

This study was a randomized, within-person, triple-blind clinical trial, in which the patient, evaluator, and statistician were masked to the group assignment. A third researcher, who was not involved in the evaluation process, was responsible for the randomization process. The patients were randomized into two treatment groups using a simple randomization process: the patients in group 1 received enamel microabrasion combined with in-office bleaching. The patients in group 2 received in-office bleaching only. All clinical procedures were performed by the same doctor, and the doctor was not involved in efficacy evaluation and data analysis. Group 1 received enamel microabrasion with 37\% hydrogen peroxide (DenFil Etchant-37, Verismo Company, Korea) and pumice (Pumice, Pumex, United Kingdom) combined with inoffice bleaching (Beyond Whitening Accelerator, Beyond, China). The patients in group 2 received in-office bleaching ((Beyond Whitening Accelerator, Beyond, China) only.

\section{Microabrasive Protocol}

The teeth of 30 patients in group 1 were micro-grinded; $37 \%$ phosphoric acid (DenFil Etchant-37, Vericom Company, Korea) was mixed with pumice stone Pumice, Pumex, United Kingdom in a ratio of $1: 1$. The mixture was placed about $2 \mathrm{~mm}$ above the affected tooth surface, and the area with a rubber cup was gently ground for about 10s. The superfluous material was removed with a sterile gauze and rinsed for $20 \mathrm{~s}$. This step was repeated 12 times. At the end of the treatment, the micro-ground teeth were polished using polishing disks (Enhance, Dentsply, USA) and polishing paste (Proxy, Ivoclar Vivadent AG, Germany), rinsed, and blow-dried. A neutral sodium fluoride (Clinpro White Varnish, 3M ESPE Dental Products, USA) was applied for $1 \mathrm{~min}$. The teeth of patients in group 2 were polished only with polishing disks (Enhance, Dentsply, USA) and polishing paste (Proxy, Ivoclar Vivadent AG, Germany). Finally, the teeth were rinsed and blow-dried.

\section{Bleaching Protocol}

The patients in both the groups received in-office bleaching They received lip balm oil; their mouths were opened with a mouth opener, and a wet silver was put in the oral vestibule. -Light-curing resin protector (Beyond) was used to isolate gingival tissue from the bleaching area. Then, 35\% hydrogen peroxide gel (Beyond) was applied to the enamel surface (15min) three times according to the manufacturer's protocol. At the end of bleaching, the whitening gel was rinsed thoroughly with an air/water spray for 30s and airdried.

\section{Evaluation of Therapeutic Efficiency}

This trial evaluated the effect on patients immediately after bleaching to avoid the effects of daily eating habits of patients, such as drinking coffee, and other factors on the treatment results. The area of fluoride staining was still measured by the blinded evaluator who collected digital photos of patients and used image software to obtain the area ratio of fluoride staining, which was compared with the fluoride staining area ratio of the baseline. The improvement in fluoride staining was compared between the two groups using the difference in the fluoride staining area before and after the treatment. Meanwhile, the patients were evaluated using VAS1 ranging from 1 (stain not removed at all) to 7 (stain totally removed) to evaluate the improvement in fluoride staining after treatment [13].

\section{Tooth Sensitivity Evaluation}

The VAS2 and sensitivity rate were used to assess the patient's sensitivity. The VAS2 ranked from 1 (no tooth or gingival sensitivity) to 5 (severe tooth or gingival sensitivity) [14]. When the patient's VAS2 score was 0 , it was considered insensitive. The other scores were sensitive, and the ratio of the sensitive population to the total population was the patient's sensitivity rate.

\section{Statistical Analysis}

After using the Shapiro-Wilk test to check the normality distribution of patient age, area ratio (a) of fluoride staining, and the difference between the fluorosis area ratio before and after the treatment $(\Delta a)$, the paired $t$ test or Wilcoxon signed-rank test was used to compare a before and after the treatment. The t test or Mann-Whitney U test was used to compare patients' age and $\Delta \mathrm{a}$. The Mann-Whitney $\mathrm{U}$ test was used to compare ranked data Dean's index, VAS1, and VAS2. The Fisher exact probability method was used to analyze patient sex and sensitivity rate. All calculations were completed by a blinded statistician using SPSS 20.0(IBM, USA), and the significance was set at $5 \%$.

\section{Result}

A total of 60 patients were included in this study (Figure 2). The baseline characteristics of patients are shown in (Table 1). No significant difference was found in age $(\mathrm{P}=0.534)$, gender ratio ( $\mathrm{P}$ $=0.143)$ and Dean's index $(\mathrm{P}=0.557)$.

Table 1: Baseline characteristics and Dean's index.

\begin{tabular}{|c|c|c|c|}
\hline Variables & Group 1 (n = 30) & Group 2 (n = 30) & P value \\
\hline Age (year, mean \pm SD) & $33.77 \pm 5.496$ & $34.70 \pm 6.075$ & 0.534 \\
\hline $\begin{array}{c}\text { Gender (female, \%) } \\
\begin{array}{c}\text { Dean's index } \\
\text { (median, P25, P75) }\end{array}\end{array}$ & $63.33 \%$ & $83.33 \%$ & 0.143 \\
\hline
\end{tabular}




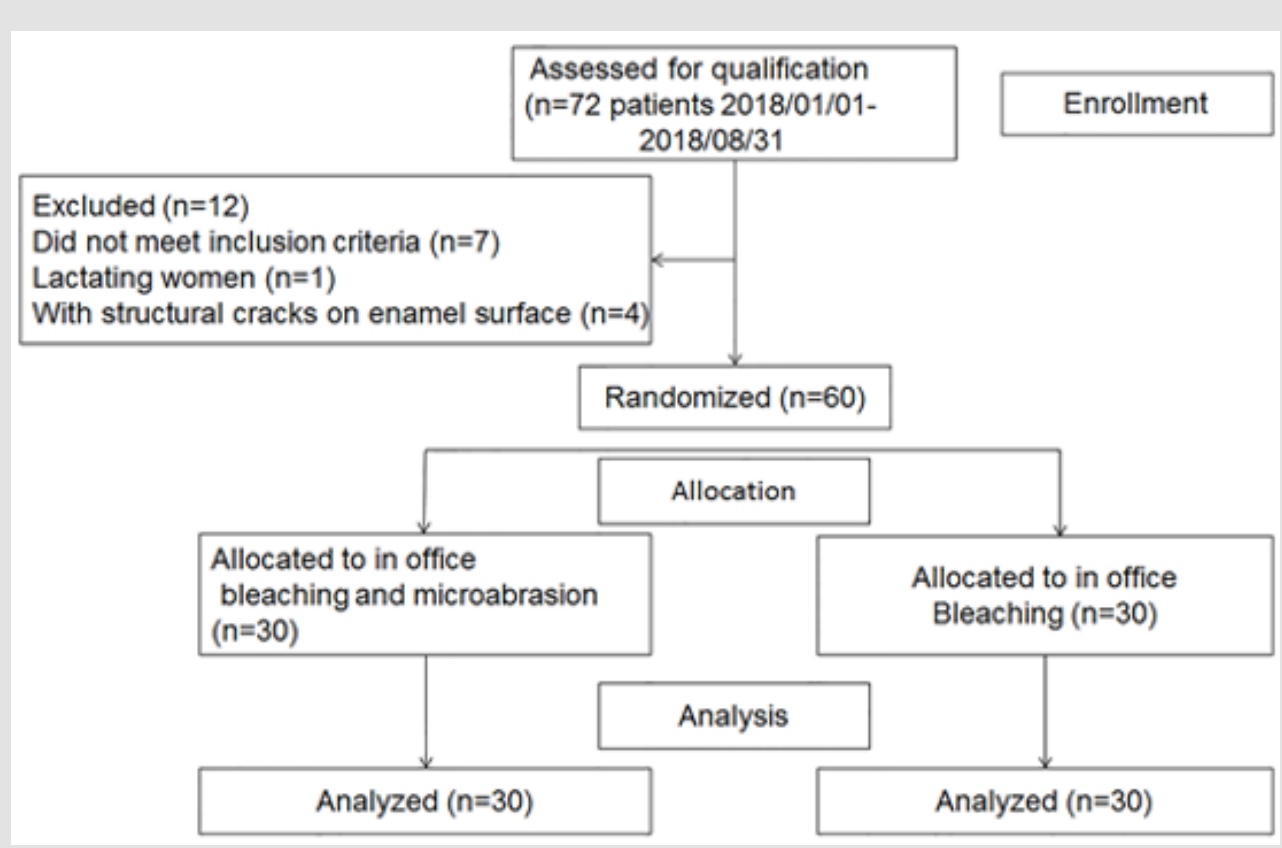

Figure 2: Flow chart of the trial.

\section{Therapeutic Efficiency Area Ratio of Fluoride Staining}

Before treatment, no significant difference was found between the two groups $(\mathrm{P}=0.145)$. Both treatments reduced the area of fluoride staining $(\mathrm{P}<0.001)$ (Table 2$)$. The difference between the decrease in the fluoride staining area of the two groups was further compared. The decrease in the fluoride staining area was $7.355(5.225,11.355)$ for group 1 and $4.08(3.107,5.683)$ for group 2. Group 1 showed more improvement compared with group 2 (P $<0.001$ ).

Table 2: Medians and interquartile ranges of fluorosis staining area ratio (\%) during different evaluation periods for groups treated with enamel microabrasion combined with in-office bleaching or in-office bleaching only.

\begin{tabular}{|c|c|c|c|}
\hline Period & Group 1 (n= 30) & Group 2 (n= 30) & PG1-G2 \\
\hline Baseline & $9.005(5.902,13.475)$ & $7.19(5.328,8.932)$ & 0.145 \\
\hline After treatment & $1.05(0.405,2.145)$ & $2.825(1.565,4.42)$ & \\
\hline Paceline-After & $<0.001$ & $<0.001$ & \\
\hline
\end{tabular}

Visual Analog Scale 1: The two groups of patients thought that the treatment had improved fluoride staining. The patients in group 1 were more satisfied with the improvement in fluoride staining compared with the patients in group $2(\mathrm{P}<0.001)$ (Table 3$)$.

Table 3: Medians and interquartile ranges of esthetic perception and the tooth sensitivity rate in the two groups.

\begin{tabular}{|c|c|c|c|}
\hline Scale & Group 1 & Group 2 & P value \\
\hline VAS1 0-7 & $5(4.25,6)$ & $4(3,5)$ & $<0.001$ \\
\hline VAS2 0-5 & $3(2,3)$ & $2(1,3)$ & 0.043 \\
\hline
\end{tabular}

Note: VAS1, Visual analog scale 1; VAS2, visual analog scale 2.

\section{Tooth Sensitivity}

Visual Analog Scale 2: The tooth sensitivity rate of patients in group 1 was higher than that of patients in group $2(\mathrm{P}=0.043)$ (Table 3).

Tooth Sensitivity Rate: Four patients (13.33\%) in group 1 had no tooth sensitivity at all, and $6(20 \%)$ in group 2 did not show tooth sensitivity. No significant difference was found in the sensitivity rate between the two groups $(\mathrm{P}=0.731)$.

\section{Discussion}

This trial explored whether in-office bleaching combined with enamel microabrasion could improve the staining of severe dental fluorosis. Compared with in-office bleaching only, the effect of inoffice bleaching combined with enamel microabrasion was better. Also, the patient satisfaction with the curative effect was higher. In previous studies, bleaching combined with enamel microabrasion were generally applied to patients with mild-to-moderate dental fluorosis [15-17]. Most of these studies evaluated the changes in the color of the staining area. For the deeply stained tooth, bleaching combined with enamel microabrasion could not completely remove fluorine. Further, the standard of evaluation was limited $[18,19]$. Bezerra, et al. [20] measured the enamel staining area using software and found that enamel microabrasion could reduce the fluoride staining area and improve the esthetic appearance of patient teeth [20]. Castro, et al. [6] compared the effect of enamel microabrasion combined with at-home bleaching. The microabrasion of enamel has an important role, but bleaching has little effect on the curative effect [6]. Knösel, et al. [21] also thought that the in-office bleaching was not a suitable treatment for dental fluorosis [21]. This was different from the results of Celik. The 
combination of enamel microabrasion and bleaching was thought to be better than simple enamel microabrasion. Also, the patient satisfaction was high, indicating an important role of bleaching in improving fluoride staining [22]. The results of this trial suggested that bleaching only improved the fluorosis status of patients, and when it was combined with enamel microabrasion, the whitening effect was enhanced. As the greatest harm of fluoride staining lies in the esthetic impact on patients, their satisfaction with their own esthetic appearance is the key objective of fluoride staining treatment. VAS is the most commonly used method for evaluating the efficacy and side effects of dental fluorosis $[13,23]$.

In this trial, VAS was used to evaluate the whitening effect. Most patients thought that bleaching could improve their fluoride staining. The patients with bleaching and enamel microabrasion were more satisfied with the curative effect. Besides ensuring efficacy, all treatments need to take into account the safety aspect. In previous studies, the composition of whitening agents was changed, including reducing the concentration of peroxide, increasing antisensitive substances, and so on, hoping to reduce the side effect of whitening, which is tooth sensitivity, without reducing the curative effect [24-28]. Tooth whitening is still considered to be a treatment with minimal damage to the structure of the teeth [29-32]. At present, enamel microabrasion is widely used in clinical practice, including dental staining for young people [33-35]. Although enamel microabrasion is considered safe in removing fluoride staining, [36] some studies found that enamel microabrasion increased the roughness of the enamel surface and led to the loss of part of the enamel [37-39]. Pini, et al. observed the morphology of the enamel using confocal laser-scanning microscopy and found that these side effects could be reversed using the polishing procedure or saliva exposure [40,41]. Paic thought that the operator's manipulation was the main factor causing the microabrasion and the polishing of the enamel surface was also important [42]. In this study, no significant difference was found in the sensitivity rate between the two groups, but the results of VAS2 indicated that enamel microabrasion could increase the degree of sensitivity of the patients.

No misoperation occurred during the treatment because the doctor was experienced. The microabrasion of the enamel may cause some damage to the tissue of the teeth [43]. The bleaching treatment was performed immediately after microabrasion. Whether the patient's sensitivity is reduced after grinding for a certain period needs further exploration. In addition, the evaluation of the patient's sensitivity is quite subjective. Some patients are not adapted to the low-rotation handpiece in the process of microabrasion, affecting the judgment of sensitivity. VAS is influenced by personal choice [44]. However, patients' experience is also a factor that should be considered by the doctors in clinical practice. The results of this trial suggested that the individual differences in the degree of acceptance of the treatment must be taken into consideration when choosing the treatment, especially for young people, because of the need to remove the 25- to $200 \mu \mathrm{m}$ enamel [43]. In this trial, the effects of different dietary habits on the results were taken into account. Therefore, only the fluoride staining areas before and after the treatment were compared. Patients with similar dietary habits should be followed up for a long time in the future. Further, this trial was a single-center study. Large-sample multicenter trials are needed to improve the accuracy and credibility of the results. Both treatments improved the fluoride staining of moderate and severe dental fluorosis. The combination of enamel microabrasion and bleaching could achieve the better curative effect. However, microabrasion should be performed gently, and attention should be paid to the feelings of the patients during the treatment.

\section{Conclusion}

In-office bleaching can improve moderate and severe dental fluorosis. The effect of the combination of enamel microabrasion and bleaching is better. The choice of treatment should take into account the patient's esthetic requirement and the individual acceptance of treatment.

\section{Conflict of Interest}

The authors declare that they have no conflict of interest.

\section{Acknowledgment}

This study was supported by This work was supported by the National Natural Science Foundation of China (81900959 to Y.J. L., 81802700 to Y.C. L.).

\section{References}

1. Pendrys DG (2000) Risk of enamel fluorosis in nonfluoridated and optimally fluoridated populations: considerations for the dental professional. J Am Dent Assoc 131(6): 746-755.

2. Molina Frechero N, Gaona E, Angulo M, Sanchez Perez L, Gonzalez Gonzalez R, et al. (2015) Fluoride Exposure Effects and Dental Fluorosis in Children in Mexico City. Med Sci Monit 21: 3664-3670.

3. Riordan PJ (1993) Perceptions of dental fluorosis. J Dent Res 72(9): 1268-1274.

4. Bortolatto JF, Pretel H, Floros MC, ACC Luizzi, AAR Dantas, et al. (2014) Low Concentration $\mathrm{H}(2) \mathrm{O}(2) / \mathrm{TiO}-\mathrm{N}$ in office bleaching: A Randomized Clinical Trial. J Dent Res 93(7): 66-71.

5. Kamp AA (1989) Removal of white spot lesions by controlled acidpumice abrasion. J Clin Orthod 23(10): 690-693.

6. Castro KS, Ferreira AC, Duarte RM, Sampaio FC, Meireles SS (2014) Acceptability, efficacy and safety of two treatment protocols for dental fluorosis: a randomized clinical trial. J Dent 42(8): 938-944.

7. Croll TP, Cavanaugh RR (1986) Enamel color modification by controlled hydrochloric acid-pumice abrasion. I. technique and examples. Quintessence Int 17(2): 81-87.

8. Joiner A (2006) The bleaching of teeth: a review of the literature. J Dent 34(7): 412-419.

9. Ahrari F, Akbari M, Mohammadpour S, Forghani M (2015) The efficacy of laser-assisted in-office bleaching and home bleaching on sound and demineralized enamel. Laser Ther 24(4): 257-264.

10. Pandis N, Chung B, Scherer RW, Elbourne D, Altman DG (2017) CONSORT 2010 statement: extension checklist for reporting within person randomised trials. Bmj 357: j2835.

11. (1997) WHO. Geneva. 
12. Chow S, Shao J, Wang H (2008) Sample Size Calculations in Clinical Research.

13. Price RB, Loney RW, Doyle MG, Moulding MB (2003) An evaluation of a technique to remove stains from teeth using microabrasion. J Am Dent Assoc 134(8): 1066-1071.

14. Matis BA, Cochran MA, Eckert GJ, Matis JI (2007) In vivo study of two carbamide peroxide gels with different desensitizing agents. Oper Dent 32(6): 549-555.

15. Celik EU, Yildiz G, Yazkan B (2013) clinical evaluation of enamel microabrasion for the aesthetic management of mild-to-severe dental fluorosis. J Esthet Restor Dent 25(6): 422-430.

16. Shanbhag R, Veena R, Nanjannawar G, Patil J, Hugar S, et al. (2013) Use of clinical bleaching with 35\% hydrogen peroxide in esthetic improvement of fluorotic human incisors in vivo. J Contemp Dent Pract 14(2): 208-216.

17. Pontes DG, Correa KM, Cohen Carneiro F (2012) Re-establishing esthetics of fluorosis-stained teeth using enamel microabrasion and dental bleaching techniques. Eur J Esthet Dent 7(2): 130-137.

18. Loguercio AD, Tay LY, Herrera DR, Bauer J, Reis A (2015) Effectiveness of nano-calcium phosphate paste on sensitivity during and after bleaching: a randomized clinical trial. Braz Oral Res 29(1): 1-7.

19. De Paula EA, Nava JA, Rosso C, Benazzi CM, Fernandes KT, et al. (2015) In-office bleaching with a two- and seven-day intervals between clinical sessions: A randomized clinical trial on tooth sensitivity. J Dent 43(4): 424-429.

20. Bezerra AC, Leal SC, Otero SA, Gravina DB, Cruvinel VR, et al. (2005) Enamel opacities removal using two different acids: an in vivo comparison. J Clin Pediatr Dent 29(2): 147-150.

21. Knosel M, Attin R, Becker K, Attin T (2008) A randomized CIE L*a*b* evaluation of external bleaching therapy effects on fluorotic enamel stains. Quintessence Int 39(5): 391-399.

22. Celik EU, Yildiz G, Yazkan B (2013) Comparison of enamel microabrasion with a combined approach to the esthetic management of fluorosed teeth. Oper Dent 38(5): E134-E143.

23. Loguercio AD, Correia LD, Zago C, Tagliari D, Neumann E, et al. (2007) Clinical effectiveness of two microabrasion materials for the removal of enamel fluorosis stains. Oper Dent 32(6): 531-538.

24. Seghi RR, Denry I (1992) Effects of external bleaching on indentation and abrasion characteristics of human enamel in vitro. J Dent Res 71(6): $1340-1344$

25. Briso ALF, Fonseca MSM, De Almeida LCAG, Mauro SJ, dos Santos PH (2010) Color alteration in teeth subjected to different bleaching techniques. Laser Physics 20: 2066-2069.

26. Kossatz S, Dalanhol AP, Cunha T, Loguercio A, Reis A (2011) Effect of ligh activation on tooth sensitivity after in-office bleaching. Oper Dent 36(3): 251-257.

27. Reis A, Dalanhol AP, Cunha TS, Kossatz S, Loguercio AD (2011) Assessment of tooth sensitivity using a desensitizer before lightactivated bleaching. Oper Dent 36(1): 12-27.

28. Sulieman M, Addy M, Mac Donald E, Rees JS (2004) The effect of hydrogen peroxide concentration on the outcome of tooth whitening: an in vitro study. J Dent 32(4): 295-299.
29. Romero MF, Babb CS, Delash J, Brackett WW (2018) Minimally invasive esthetic improvement in a patient with dental fluorosis by using microabrasion and bleaching: A clinical report. J Prosthet Dent 120(3): 323-326.

30. Moncada G, Sepulveda D, Elphick K, Contente M, Estay J, et al. (2013) Effects of light activation, agent concentration, and tooth thickness on dental sensitivity after bleaching. Oper Dent 38(5): 467-476.

31. Wang Y, Sa Y, Liang S, Jiang T (2013) Minimally invasive treatment for esthetic management of severe dental fluorosis: a case report. Oper Dent 38(4): 358-362.

32. Hegedus C, Bistey T, Flora Nagy E, Keszthelyi G, Jenei A (1999) An atomic force microscopy study on the effect of bleaching agents on enamel surface. J Dent 27(7): 509-515.

33. Wallace A, Deery C (2015) Management of Opacities in Children and Adolescents. Dent Update 42(10): 951-954.

34. Souza de Barros Vasconcelos MQ Almeida Vieira K, Da Consolacao Canuto Salgueiro M, Almeida Alfaya T, Santos Ferreira C, et al. (2014) Microabrasion: a treatment option for white spots. J Clin Pediatr Dent 39(1): 27-29.

35. Sundfeld RH, Sundfeld Neto D, Machado LS, Franco LM, Fagundes TC, et al. (2014) Microabrasion in tooth enamel discoloration defects: three cases with long-term follow-ups. J Appl Oral Sci 22(4): 347-354.

36. Allen K, Agosta C, Estafan D (2004) Using microabrasive material to remove fluorosis stains. J Am Dent Assoc 135(3): 319-323.

37. Tong LS, Pang MK, Mok NY, King NM, Wei SH (1993) The effects of etching, micro-abrasion, and bleaching on surface enamel. J Dent Res 72(1): 67-71.

38. Rodrigues MC, Mondelli RF, Oliveira GU, Franco EB, Baseggio W, et al. (2013) Minimal alterations on the enamel surface by micro-abrasion: in vitro roughness and wear assessments. J Appl Oral Sci 21(2): 112-117.

39. Fragoso LS, Lima DA, De Alexandre RS, Bertoldo CE, Aguiar FH, et al. (2011) Evaluation of physical properties of enamel after microabrasion, polishing, and storage in artificial saliva. Biomed Mater 6(3): 035001.

40. Pini NI, Lima DA, Ambrosano GM, da Silva WJ, Aguiar FH, et al. (2015) Effects of acids used in the microabrasion technique: Microhardness and confocal microscopy analysis. J Clin Exp Dent 7: e506-e512.

41. Pini NIP, Lima D, Sundfeld RH, Ambrosano GMB, Aguiar FHB, et al. (2017) Tooth enamel properties and morphology after microabrasion: an in situ study. J Investig Clin Dent 8(2).

42. Paic M, Sener B, Schug J, Schmidlin PR (2008) Effects of microabrasion on substance loss, surface roughness, and colorimetric changes on enamel in vitro. Quintessence Int 39(6): 517-522.

43. Sundfeld RH, Croll TP, Briso AL, de Alexandre RS, Sundfeld Neto D (2007) Considerations about enamel microabrasion after 18 years. Am J Dent 20(2): 67-72.

44. Vieira AP, Lawrence HP, Limeback H, Sampaio FC, Grynpas M (2005) A visual analog scale for measuring dental fluorosis severity. J Am Dent Assoc 136(7): 895-901. 
ISSN: 2574-1241

DOI: 10.26717/BJSTR.2021.34.005510

Shaohai Chang. Biomed J Sci \& Tech Res

(c) (P) This work is licensed under Creative

Submission Link: https://biomedres.us/submit-manuscript.php

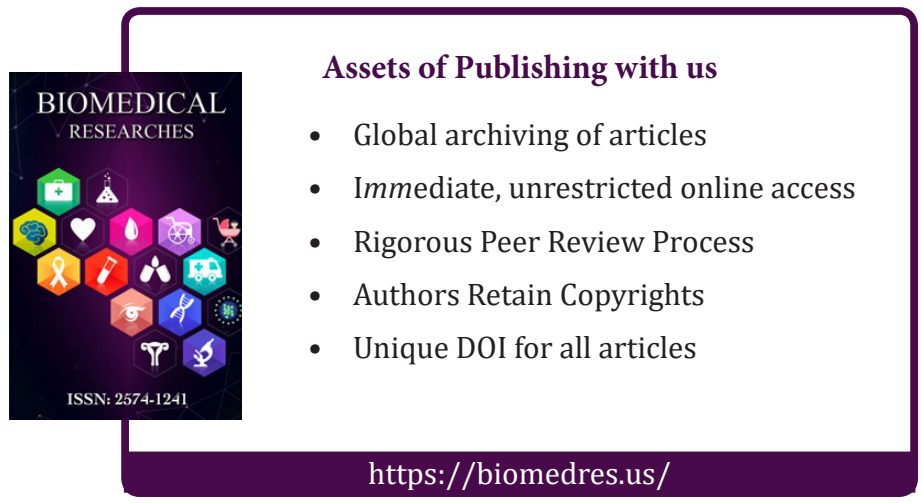

